\title{
Usage and Impact Metrics for Parliamentary Libraries
}

\section{Author:}

\section{Tarek Al Baghal}

Institute for Social and Economic Research

University of Essex

Colchester, UK

CO4 3SQ

ph: +44 1206874781

email: talbag@essex.ac.uk

\begin{abstract}
Parliamentary libraries are important in supporting informed decision-making in democracies. Understanding Members' information needs is important, but indicating the usage and impact of these libraries have been explored less. A particular example of the United Kingdom's House of Lords Library is studied, collecting and analyzing data using techniques from the field of data science. These techniques are useful in extracting information from existing sources that may not have been designed for the purpose of data collection. A number of data sources available at the Lords Library are outlined and an example of how these data can be used to understand Library usage and impact is presented. Results suggest that Member usage varies significantly and that there is a weak relation to usage to making speeches in chamber. Further work should explore other indicators of impact, but these methods show promise in creating library metrics, particularly in Parliamentary settings.

keywords: Parliamentary Libraries, House of Lords Library, metrics, data science, usage, impact
\end{abstract}

Acknowledgements: The author is funded by a research award from the UK Economic and Social Research Council (award no. ES/M500537/1) for "Impact Acceleration Account 2014 - University of Essex." 


\title{
Usage and Impact Metrics for Parliamentary Libraries
}

\begin{abstract}
Parliamentary libraries are important in supporting informed decision-making in democracies. Understanding Members' information needs is important, but indicating the usage and impact of these libraries have been explored less. A particular example of the United Kingdom's House of Lords Library is studied, collecting and analyzing data using techniques from the field of data science. These techniques are useful in extracting information from existing sources that may not have been designed for the purpose of data collection. A number of data sources available at the Lords Library are outlined and an example of how these data can be used to understand Member usage and potential Library impact is presented. Results suggest that Member usage of the Library varies significantly and that there is a weak relation to usage to making speeches in chamber. Further work should explore other indicators of impact, but these methods show promise in creating library metrics, particularly in Parliamentary settings.

keywords: Parliamentary Libraries, House of Lords Library, metrics, data science, usage, impact
\end{abstract}




\section{Introduction}

Providing evidence of a library's usage and impact is an important process to inform policies on how to improve services and ensure that resources are appropriated allocated. Special libraries, including Parliamentary libraries, are not unique in this regard, but the population these cater to and services provided are in some ways, in particular in the need to provide information services. Parliamentary libraries in particular have the goal of providing full and unbiased information to members in order to aid decision-making (Watt, 2010).

What the information needs of Parliamentary members are exactly, and how these should be provided, are frequently changing and specific to the institutional context the library works within. Generalizing beyond the need for Parliamentary libraries to provide information to aid members' decision-making this need is difficult. First, generalizing to a broader context can be difficult because the nature of who the Parliamentary library serves can vary between countries or governments (Brundin, 2005; Marcella et al., 1999). Second, the make-up of Parliamentary houses can be diverse, where the members come from myriad backgrounds, contexts, constituencies, and preferences (Orton et al., 2000).

Further, the information needs of members can differ across governments. An example is the early role of the Hungarian Parliamentary library, which fostered the nascent democratic processes (Ronai and Bryant, 1992). The needs described in that particular research will be different in more developed democracies, including modern Hungary (e.g. Kohl, 1991). Changes in technology have changed the nature of information available to Parliament, both internal and external to the Parliamentary library (Missingham, 2011; Missingham and Miskin, 2011; Watt, 2010). However, the use of technology and existing data sources has been more limited in other countries' Parliaments such as Ghana (Alemna and Shouby, 2000), South Africa (Mostert, 2005), India (Zafar, 2009), and Tanzania (Manda and Hilika, 2016). Given the rapid change in adoption of technology and changes in the needs and contexts of Parliamentary members, use of these additional sources of information may have already changed dramatically.

While studies have focused on the needs of Parliamentary members and the role of Parliamentary libraries in providing information in response to these needs, significantly less research has focused on actual library usage and the impact these libraries have, generally and specifically among members. The present study explores the usage and impact of the United Kingdom's House of Lords Library, particularly among the Members, and provides 
examples of how these metrics can be developed and used. The exploration of the Lords Library is unique as the chamber it serves, the House of Lords, has a particular role in governance. Further, a research on UK Parliamentary libraries has focused on the role of the House of Commons Library (e.g. Comma Serema, 1999; Orton et al., 2000). The description of current data collected and additional sources are identified, and "Big Data" techniques are employed to extract and analyze data collected, as the data available was not generated for analytic purposes, and are largely unstructured in this sense (Gandomi and Haider, 2015). Results suggest possible avenues of data collection for usage and impact of Parliamentary (and potentially other) libraries, and how these data can be used to understand the potential impact these libraries have on governance.

\section{The House of Lords Library}

The House of Lords is seen as a "historical curiosity" (Russell, 2010:866), although it still has an important role in UK governance (Norton, 2003; Russell, 2010; Russell and Sciara, 2007). The number of Members of the House of Lords is not fixed; new Members are added periodically through nomination by the public and political parties. The Prime Minister must approve nominations, after which appointments are formalized by the monarch. Most appointments are made for life (Life Peers), although by definition are not hereditary. There are still a small number of Hereditary Peers. The House of Lords Act of 1999 reduced the number of Hereditary Peers by more than 600, setting the maximum number to 92 . The remainder of Members is clergy (Bishops). Currently there are 791 Members of the House of Lords: 676 Life Peers, 90 hereditary Peers, and 25 Bishops. In comparison, there are a set number of 650 Members of Parliament in the House of Commons, although future legislation aims to reduce this number to 600 MPs (Johnston, 2017).

Bills passed by the House of Commons needs the assent of the Lords, although this been limited and can in some instances be overridden by the Commons, through the Parliament Acts of 1911 and 1949. The 1911 Act removed the Lords' absolute veto power on money bills, while the replacing it with powers of delay, with the 1949 Act extending similar rules to all other public bills (Shell, 2007). Like many other second chambers, it works extensively on legislative revision, making numerous amendments to bills which are largely accepted by the House of Commons (Norton, 2003). The House of Lords also provides administrative 
oversight, and can debate issues the House of Commons does not have time to do, having a limited role in setting the legislative agenda.

Given this role, Members of the House of Lords need information relevant to the numerous bills and duties they are presented with by the House of Commons and issues facing the nation. As such, the House of Lords Library provides important information services to Members as the House of Commons Library does for Members of Parliament (MPs)..

The Lords Library was established in 1826, with limited services provided. In 1977, a working group was formed to modernize services, which are the basis of the services provided to Members today (Greenhead, 2014; Purvis, 2017). These modernizations included staff appointed to provide in-depth research for the members, and recruitment of professional librarians to look after reader and technical services (Greenhead, 2014). In addition to library services such books, journals, and special collections, the Lords Library also provide planned or bespoke research services (Purvis, 2017). Planned outputs focus on important upcoming debates or topics in the news, and are released as reports and materials under the titles of Lords Library Note, Lords in Focus, or Lords Briefing Packs (although Lords in Focus are becoming subsumed into the Lords Library Note title going forward). The Library also produces the Current Affairs Digest, a monthly digest of articles from the Library's academic journal subscriptions, from blogs and magazines, plus speeches and think tanks. All of these materials are electronically available online and sent to individuals via by request, with all Members signing up to speak in debates sent research materials relevant to that particular speech . Paper copies are also left in open reading spaces throughout the Library.

While no direct research on the information needs of Lords was identified, it can be reasonably assumed that in many ways these needs are similar to those of MPs, given the same legislation, administrative issues, and issues facing the nation. The information needs of MPs, and hence the pressures on Library services, are complex and multifaceted (Comma Serema, 1999; Orton et al., 2000). It has been noted (Comma Serema, 1999:187) these "needs can vary depending on what is happening nationally, internationally, and what is going on in Parliament." Case studies and surveys both show the importance of the Commons Library in providing information to MPs in a variety of ways (e.g. background for informed voting, research for speechwriting, constituency casework, Parliamentary business) (Comma 
Serema, 1999; Orton et al., 2000). The limited amount of data available is suggestive that Members have varied information needs and make use of the services of the Lords Library. In 2016, 734 Members used the Library for at least one service, including the Library answering more than 3000 enquires, providing nearly 1700 bespoke research requests, loaning 1457 books (Purvis, 2017). Additionally, the Lords Library added nearly 1700 new titles to its catalogue in 2016 (Purvis, 2017).

While Members clearly have particular information needs, which are likely to be similar to those in the House of Commons, several notable differences apply to Lords Library compared to the Commons Library. First, the role of the House of Lords itself is different from the House of Commons in terms of governance, as noted above. The House of Lords devotes significant time to revising legislation proposed in the Commons, administrative oversight, and debate, while its assent is required to bills passed by the Commons (Norton, 2003; Russell, 2010). Second, Members do not have a constituency per se, and do not have electoral pressures. As such, there is less pressure to adhere to party cohesion (although Members frequently do) (Norton, 2003). The Lords Library is also smaller in size and has fewer staff than then Commons Library, even though there are more Members of the House of Lords than in the House of Commons. As such, the 45 staff members of the Lords Library are generalists that must produce work on a broad array of topics, while there are a number of topic specialists in the Commons Library.

In order to better provide services to Members, the Lord Library began a project to better develop metrics for usage and impact of its services. Given the extent of resources, both in terms of person-hours and financial, the Library sought to exploit existing data to develop these metrics. There is limited research on how to collect these metrics using existing data generally at libraries, with little work specifically conducted in Parliamentary libraries. As such, the following section outlines work done to bridge this gap, particularly in Parliamentary libraries, using the project undertaken at the House of Lords Library as a demonstration.

\section{Parliamentary Library Metrics Using Data Science}

There is an array of literature outlining the myriad methods to measure and evaluate libraries generally, including quantitative, qualitative, or mixed-method approaches. These can evaluate the library holistically or only certain aspects of performance. These methods have 
been covered extensively (e.g. Appleton, 2017; Poll and Payne, 2006), and the focus here will be on research on special libraries, in particular Parliamentary libraries. These libraries have unique pressures and the impacts are different from other contexts. For example, academic libraries may be interested in measurables such as student outcomes (like exam grades) or staff outcomes (such as publications and H-indices) (Showers and Stone, 2014).

Parliamentary libraries provide additional services, such as research on specific topics, and the outcomes are more difficult to measure. In particular, the overall goal is to aid informed governance, and how this is best indicated is not directly obvious.

Other indicators have therefore been suggested. In the UK House of Commons, Comma Serema (1999) noted the use of a complaints system and the potential for regular user surveys to indicate Library performance. A form of survey, the Contingent Valuation Method (CVM), has also been suggested for special libraries generally (Chung, 2007; Missingham, 2005). However, CVM and surveys generally can be costly and time consuming (Missingham, 2005). Surveys and complaint systems also can miss important information from those members not participating. These self-reporting mechanisms are also somewhat limited by memory and perceptions of use and impact.

These types of data collection also do not take advantage of records, information, and data already collected in a variety of forms as part of everyday library processes. Frequently these records and data are not generated for research or analytic purposes, so the methods such as those used in field of "Big Data" need to be applied to turn these into meaningful metrics. These existing data are not affected by memory or perceptions (although can be affected by other problems), and given these are already being collected for other purposes, the additional cost is low.

To explore the possibilities of creating and using such measures, the House of Lords Library, through the UK Parliamentary Office of Science and Technology (POST), set up a project for a researcher at an academic institution (the author) to undertake as a Parliamentary Academic Fellow. The goals of the project, as outlined in the call for applications, were:

To ensure that the research services that the Library provides are both appropriate and effective, the Library collects a number of different types of data on the services it provides and more limited data on how these services are being used by its customers. The aim of this Project is to assess the appropriateness and usefulness of the data being 
collected by the Lords Library to monitor and evaluate its performance, effectiveness and impact. It is envisaged that this will involve:

- Establishing what data is currently collected, by whom and for what purpose.

- Identifying the types of information and data that would be useful for the Library to collect, and the methods that might be used for such purposes, in order for it to be able to systematically and rigorously assess its performance, effectiveness and impact.

- Using examples of current or best practice from elsewhere, identifying whether there are accessible, free or low-cost IT solutions available, in particular for analyzing the data quickly and easily.

A variety of avenues were followed to create and analyze data from a number of data sources. Some of these were informed by discussion with Library staff, while others have been independently generated. The goal of the data creation was to identify the usage of Library services (quantity) and the impact these services have, particularly among Members (quality). All of the work was conducted in R, a freely-available programming and statistical computer program. The R program has a large number of developed packages that allow for extraction and manipulation of complex data as well as powerful statistical analyses (R Core Team 2018). The following list describes major sources of data and how these were extracted and manipulated in order to create usable metrics.

\section{Lords Whips site for speaker list}

To speak during a scheduled debate, Lords sign-up via the Lords' Whips website (www.lordswhips.org.uk). Lords that sign-up are recorded on a daily basis by Library staff and sent the relevant research materials for a given debate (i.e. Research Notes, Lords in Focus, or Lords Briefing Packs). Besides direct individual requests, this sending based on sign-ups is the only systematic measure of usage (at least receipt) of these materials. Downloads from the internet cannot be linked directly to an individual (although this still can produce useful information as discussed below), while counts of remaining paper copies tell only how many were taken, not by whom or if some copies were read and returned. Therefore, counts of sign-ups are a basic metric of usage.

Originally, these counts were done manually. A person would visit the Whips site each day recording the signed up speakers and the debate and date for the speech. This process has 
been automated using $\mathrm{R}$, using the package $\mathrm{XML}$ where the program scrapes the page the website each time it is run. The program outputs a list of unique entries for speaker/debate/date combinations. This program can be automatically scheduled to run at any given interval, using the package taskscheduleR. The inputs to the program (specifically start of week dates) can be set to run indefinitely, as long as the website does not change the underlying HTML/XML code in a significant way. It is likely that is will change at some point, at which point the program would need to be adjusted accordingly.

\section{EDDIS request system}

The Lords Library has used the customized Enquiries Database Department of Information Services (EDDIS) system to log all requests made, including any research queries. A new customized system Library Enquiries Tracking System (LETS), has been developed for the Library to capture requests going forward, but the important data captured is similar in nature. The system provides data outputted in easily used comma-separated values (CSV) files. The reports provide a number of variables that can be summarized in a useful manner. Importantly, the measures include the number of enquiries made by each Member, the channel to make these requests (e.g. at the Library desk, email) overall and by each Member, and the types of enquiries made (e.g. research enquiry, printing, press search) overall and by each Member. As such, the analysis of requests as an outcome on its own is rather straightforward; however, potentially more understanding can be understood about usage and impact if this request system data is linked to other (and new) data sources.

\section{Symphony library records}

Previously, the Library used the SisriDynix Symphony integrated library system to log book and other Library material loans (SirsiDynix, 2018). The version of the system used generated reports of current loans, including by user, but it did not produce reports of historical loan data. This limited understanding how Library holdings were being used. Symphony does contain records of all old loan records in its system (unless explicitly purged) creating a log of these in text format. The log is not structured in a way to immediately use for analysis of any sort. An example entry in this log is as follows:

327.41 BEN copy: 1 005240

Six moments of crisis : inside British foreign policy / Gill Bennett. Bennett, Gi11.

$\begin{array}{lcl}\text { Jones (on beha1f of XYZ } 3 / 3 / 2016,12: 32 & 28 / 4 / 2016,23: 59 \\ 12 / 4 / 2016,11: 13 & 0 & 0\end{array}$ 
The first line of text includes information call number (and which copy, for cases where there are more than one copy); the second line includes book title and author; the third line repeats author information; the fourth line includes user ID making the loan (e.g. XYZ), date/time of checkout and due date; the fourth line includes date returned, and counts of renewals, overdue notices, and recalls. With more than ten thousand such records, manual counting of this type of information is not feasible. However, there is a structure to the records. This structure was leveraged to parse the text in $\mathrm{R}$ and turn these records into flat records (one row per record), with columns for each piece of information noted across the rows of the record. This provided the possibility to extract a number of potentially useful measures, including usage by the Members directly. These include:

\section{a. Loans and length, by user or book}

Number of loans can now easily be made, overall, by book or by user ID. An additional database linked user IDs to names and status within the House of Lords (e.g. staff, Member). Additionally, information about the when loans were made, how long each loan was made, and the overall number of days books were loaned can be made by book or by user. Important to the current work, this user can be identified at the Member-level, and can be linked to other Member-level data.

\section{b. Count loans by book type by user}

The call number can also be extracted, such that these can be linked to the categorizations of the Dewey Decimal system. While any level of discrimination of the call number could be made (e.g. by units, tens, or hundreds) using this method, the current work classified books at the broadest level, i.e. by the hundreds classification. Now counts of what kinds of topics/books can be made overall and by individual users. This data is also recorded at the Member-level.

\section{c. Link NBARN data to loans}

Using the above information, data from the loan record was linked to information about new library holdings, disseminated by the New Books and Resources Newsletter (NBARN), to identify if new holdings are being loaned following this dissemination. As an initial example, 
a list of books listed in the NBARN for November 2017 was provided, and these books are linked to the loan record by call numbers. This allows for counts of number of loans of each new resource or what has not been used, and by which users. This work can be extended to all editions of the NBARN as desired.

The Lords Library recently switched its library system from Symphony to Koha, an opensource integrated library system, which contains a reporting system that more easily generates these types of information (LibLime Koha, 2018). The more readily outputted data from this reporting system will make these kinds of analyses more direct in the future.

\section{Google Analytics raw data}

The UK Parliament uses Google Analytics to track usage of the Parliamentary web site, which collects a data along a number of possible metrics and domains (see https://developers.google.com/analytics/devguides/reporting/core/dimsmets for information on metrics and domains).

While these data are available through the Google Analytics dashboard, analyses can be somewhat difficult given the lack of raw data and tools to analyze these in customized ways. The $\mathrm{R}$ package googleAnalytics $\mathrm{R}$ allows for importing raw data in a customized manner into $\mathrm{R}$, allowing for additional analyses. This was done by extracting information about the web pages hosting Lords Library Notes, Lords in Focus, and Lords Briefing Packs. These could be separated given the systematic structure of the webpages hosting each of these pieces (i.e. Lords Library Notes have lln- in the url, Lords in Focus, has lif- in the url, and Lords Briefing Packs has lbp- in url). Information about these pages could be extracted in regards to the metrics and domains of interest. The initial set of information collected includes:

\section{a. Count web hits for Library research output}

Given the raw data, the number of site hits for each research output can be identified, both as total hits and unique visitors. Interestingly, the most visited page for research for 2017 was a 2015 piece, "Impact of Pornography on Society" (http://researchbriefings.parliament.uk/ResearchBriefing/Summary/LLN-2015-0041)

\section{b. Count web hits by location and domain}


As a step further, it can be identified where these research outputs are being accessed, through the domain accessed and geographic location recorded. This is useful in identifying internal Parliamentary usage (domains of parliament.uk) and external usage (including global reach). There is some limitation to this, as Parliamentarians and staff may access the site from external servers, as well as using VPNs or other methods to obscure IP addresses and location. However, it does provide a good picture of usage.

\section{c. Link counts to author, other briefing data}

Additional information from internal Library data about the research outputs have also been linked to website usage data. These additional data include author(s) of each output, title, date of publication, and summary. This provides more detailed records of outcomes, as well as allowing for different analyses. For example, the number of page hits by author(s) can show which pieces by which author or topics have the greatest usage/reach.

\section{Hansard}

The Hansard system provides a verbatim record of Member speeches made in Parliament, with searches available on the UK Hansard website (hansard.parliament.uk) or the Parliamentary search website (search-material.parliament.uk). The new Parliamentary Search tools allows for significantly easier to use data. In particular, the data is output in CSV format with a number of variables, including speaker, date, debate, and text. The number of speeches a Member makes overall may be useful to explore potential impact. If there is a relationship between activity (speeches in this case) and Library usage, this could suggest the nature of information used by the Members in chamber.

A further potential indicator of the Library's impact is Members referencing it in a public way. Hansard provides one such source of data. If the Library is mentioned during a speech in the House of Lords, this would indicate some impact. A number of terms were included in the initial searches for mentions in the Hansard system since 2010. These terms were Lords Library, Library Note, Library research, and Vollmer, the current head librarian. The last is an example of where specific and unique terms may identify mentions - for this example, three mentions were made since 2010. For the following initial analyses, only counts of total speeches were used, to identify the relationship between Library usage and chamber participation. 


\section{a. Counts of speeches and mentions by speaker}

Two forms of this were used initially. The first is the total number of speeches a Member gives in a given period. The second method counts the number of mentions of a specific phrase of interest a Member makes of a particular period; in the initial instance, Lords Library. The data shows if some Members are more active in chamber or make more references than others, if others make no reference, what speeches these occur in, etc.

\section{b. Sentiment analysis of speeches}

After collection of the relevant speeches, the text can be analyzed using sentiment analysis, creating quantifiable information. Sentiment analysis techniques readily available in $\mathrm{R}$ were used to create this data, using the tidytext package and the Afinn and Bing sentiment lexicons (Silge and Robinson, 2017). This data and analysis explores whether the overall tone of the speech is positive or negative. While the data does not directly measure whether the Library is being mentioned positively or negatively, it does give a picture of the context the Library is mentioned. Further, analyses can be conducted overall (across all mentions/speeches), by individual speakers, and/or by individual debates. The latter is important to at least control for, as it may be expected some debate topics may be laden with more negative terms while others use many more positive terms.

In addition to this sentiment analysis, other techniques such as n-gram correlations and topic modelling can also be conducted on these texts. $\mathrm{N}$-grams are the number of words in a phrase (e.g. 2 words is a bigram, 3 words a trigram, etc.). This analysis focuses more specifically on the terms of interest (Lords Library), to identify if these are being mentioned frequently with other specific terms. Topic models are another statistical method in text mining to discover the hidden semantic structures in a given text. This method can also be used as a next step to identify if certain topics are arising in speeches using the key terms regarding the Library. These analyses can potentially further understanding of when the Library's service influences debate.

\section{News and Social Media Mentions of the Library}

Besides speeches in the House of Lords, Members and others can also reference the Library through other means. Such mentions may come through press coverage or through social 
media use. As such, searches for similar terms were done of both news sources and social media, in a limited manner.

a. News

To identify mentions in the news, a Google Alert was set up to identify stories that include at least one of the following terms: "House of Lords Library", "Lords Library", Lords Library briefing, Lords Library note, and Lords Library research. A small number of pieces, six in total, were identified. Three of these mentions are positive mentions in opinion pieces written by Members in news outlets, while the others are news pieces citing Library research. Other news sources, such as LexisNexis, may be a more thorough way to identify such mentions, but are not directly available without cost. Given the relatively small number, these pieces can be used as exemplars of impact, as well as being easily hand coded into a larger database of Member and general usage.

\section{b. Twitter}

Another source where the Library's services may be mentioned is on social media. Currently, only Twitter is being explored, largely due to the platform's accessibility for such searching. Using the twitteR package in $\mathrm{R}$, the following terms are used to search Twitter and scrape data about relevant tweets: @ UKHouseofLords library, "Lords library", "Lords library", "@UKHouseofLords Library", "HOL library".

Data scraped from Twitter includes the text of the tweet, the user ID, whether it is a retweet, how many times it has been retweeted, and how many times the tweet has been favorited. Again, the number of identified relevant instances is small, currently forty-one cases. Text analytics techniques, described above, can also be used on these tweets, which is a possible further step. Additionally, to the extent that user IDs can be linked to Members, these data can be integrated into the larger database of usage. While none were identified as being done by a Member, it is still indicative of potential impact the Library has generally.

\section{Sentiment analysis of research outputs}

Based on the sentiment analysis presented on Hansard speech text, it was requested to similarly analyze several of the written research outputs, with sixteen initially being used. The goal was to identify whether the reports are using overly positive or negative tone in the 
writing. The results can be explored overall or by report, allowing for control of the topic being covered. Generally results suggested that reports were not overly positive or negative. The mean difference between positive and negative scores using the Bing lexicon was 26.1, a relatively small positive score. As a next step, the reports could be stripped of quoted text, to explore only original writing by Library researchers. By doing so, the data can also be linked to individual authors to identify writing patterns, if topics are controlled.

\section{Combination of various data sources}

While some analyses have been conducted on individual data sources, such as the EDDIS data, the combination of these myriad data sources allow for much richer analyses and understanding. For example, linking when a Library Note has been sent to a Member to data from Hansard can show the potential direct relationship sending these notes have. Other questions that could be explored include: are Members who make more requests also the ones signing up for more speeches, and are they making more mentions in chamber? Are those taking Library loans also making more requests, or making more mentions, and if so, what is the sentiment of these mentions? These are a small number of contrived examples, but hopefully the point of possibilities is made.

In order to show the potential of doing this, a data set was created for the fiscal year June 1, 2017 - March 31, 2018 (when the Easter break began). In particular, to analyze the impact on Members, only Member-level data was used to create this combined data set. Therefore data such as from Google Analytics, while informative and useful, could not be used in this particular example. Similarly, press and Twitter mentions, while useful exemplars are too few to include in quantitative analysis and are not included. Rather, EDDIS data, number of signups on the Whips' page, library loan data, and speeches found in Hansard are combined at the Member-level.

Some difficulties arose when creating this data set. The most common and problematic issue is inconsistency across data sources in recording identifiers, or the 'key', which are needed to match-link across data sets. For example, Member names can be listed as Lord Smith, Smith L, Smith, L., or L Smith. All of these need to first be made consistent, including the use of punctuation marks such as commas and periods or the program will not match records. Of particular difficult was linking the Koha data, which did not have formal title, like other databases, only the individual's full name. This needed to be used as a key to link to another 
data set also containing this information and the formal name, which could then be linked to other data using the formal name. This led to some slippage in linkage, and hand correction was needed to link Koha data to other data for 28 cases. Another 17 cases were duplicated in the final data set due to minor differences in the linkage key, and these were merged into one case each. There are other inconsistencies in the various data sets, such as the recording of date/time. While these problems increase difficulty and introduce greater potential for linking errors, a data set was successfully created, and the following analyses show the potential usefulness of using these created data to understand the Library's usage and impact.

\section{Analyses of Member-level Data}

Table 1 shows the means, standard deviations, and minimum and maximum value in fiscal year 2017-18 for the number of speeches made overall, the number of book loans by call number 100 series, book loans overall, the average number of days each book loan was made by individuals, and the number of research requests. For each except means days per loan the number of cases equals 780; days loaned is limited to those actually making at least one loan, and the number of cases is 186 .

Table 1: Mean Member Usage of Library and Speeches FY2017-18

\begin{tabular}{c|cccc|}
\hline \multirow{2}{*}{000 series loans } & Mean & Std. Dev. & Minimum & Maximum \\
\cline { 2 - 5 } 100 series loans & 0.005 & 0.088 & 0 & 2 \\
200 series loans & 0.014 & 0.179 & 0 & 4 \\
300 series loans & 0.014 & 0.192 & 0 & 4 \\
400 series loans & 0.260 & 1.051 & 0 & 12 \\
500 series loans & 0 & 0 & 0 & 0 \\
600 series loans & 0.004 & 0.107 & 0 & 3 \\
700 series loans & 0.009 & 0.094 & 0 & 1 \\
800 series loans & 0 & 0 & 0 & 0 \\
900 series loans & 0.006 & 0.095 & 0 & 2 \\
No call number loans & 0.271 & 1.011 & 0 & 20 \\
Total book loans & 0.391 & 1.765 & 0 & 49 \\
Days/checkout & 0.971 & 3.393 & 0 & 237 \\
\hline
\end{tabular}




\begin{tabular}{|c|cccc|}
\cline { 2 - 5 } Research Requests & 6.438 & 13.023 & 0 & 143 \\
Speeches overall & 17.238 & 35.813 & 0 & 338 \\
\hline
\end{tabular}

First, it is clear that a number of Members do not utilize the Library, according to these metrics. All of the minimum values are zero for each indicator, and the mean for book loans is generally low, with an overall mean of book loans within the year of slightly less than one per Member (with a median of 0). There were no books in the 400 series (language) and 700 series (arts and recreation) checked out, which may be because these are less related to issues of governance. Conversely, 900 series (history and geography) and holdings with no call numbers (such as journals or special collections) had the highest mean when total loans are broken down by type; these may have the higher relation to governance during this term.

Second, it is equally clear there is a large variation in Library usage among the Members. In most cases, the standard deviation is several times larger than the mean, while some of the indicators have quite large ranges. For example, the while the mean number of research requests is more than 6 , the standard deviation (13.0) and range (0-143) indicate that some Members make high use of the Library research services, while others made no requests at all. Similarly, some Members are highly participatory in the chamber in terms of speeches, while others never speak during the fiscal year.

To initially show how these usage measures are related and how usage may be related to participation, a correlation matrix is presented in Table 2 . To simplify presentation, and given the relatively small means within each hundred series, only total checkouts are used, as are mean days of checkout, number of research requests, and how many speeches were made in fiscal year 2017.

Table 2. Correlation matrix between usage and speeches

\begin{tabular}{cccc}
\hline \multirow{2}{*}{ Days/checkout } & Total book loans & Days/checkout & Research Requests \\
\cline { 2 - 4 } & 0.030 & -- & -- \\
Research Requests & 0.460 & -0.007 & --- \\
Speeches overall & 0.008 & -0.098 & 0.061 \\
\hline
\end{tabular}

Generally, the correlations are quite low, with one exception. The number of research requests are significantly correlated with book loans, with $r=0.46(\mathrm{p}<0.001)$. Particularly in 
relation to the other small correlation coefficients, this relationship suggests that Members are generally Library users, taking advantage of all its services, or conversely, less likely to use any services. However, the correlation still shows there is a reasonable amount of variation, such that there are some Members using one or the other service which does not directly correspond to their usage of the other service.

Interestingly, the only other marginal statistically significant correlation is between the number of research requests and number of speeches made $(\mathrm{p}<0.10)$. The correlation is small, $r=0.06$, but is positive, suggesting a small but existent relationship, where more requests for research in the Library is related to more speeches given in chamber.

\section{Conclusions}

Parliamentary libraries seek to serve members in a number of ways to assist in informed governance. However, the route that these libraries have on governance is not always clear. The outcomes of Parliamentary library usage and impact have been less studied, partly to the unavailability of data measuring these outcomes. Methods such as contingent-valuation or satisfaction surveys require additional data collection, and can be costly. An alternative is to develop potential measures of usage and impact based on currently existing data which is being created for a variety of purposes within the library. These data can be extracted and converted into meaninnful metrics using "Big Data"-type of methods using freely available software.

The current research explores the use of existing library data to create measures of usage and impact through the example of the UK's House of Lords Library. To date, little work has explored this particular institution, which has a unique role in governance. The House of Lords Library serves Members in their advisory role to the more powerful House of Commons. The Lords Library is smaller in size than its counterpart, the House of Commons Library, although it serves more Members. Given its size, the Lords Library provides library services including both planned and bespoke research with a staff of generalists, able to answer the myriad questions that may arise in governance.

In conducting these library services, data are being generated as by-products which may be informative to the usage and impact of the Lords Library. A variety of data sources were explored, which may similarly be available in other Parliamentary settings. These variety data 
sources were then linked to show an example of the types of analyses that could be conducted to understand library outcomes. There are issues of in linking these data sources, but once these are linked, analyses show how these data can improve understanding of how libraries, in particular those in Parliaments, are used. Other statistical analyses of such data may also inform greater understanding useful for informing future library policies.

Important in ensuring the usefulness of such data is the capture of data, which should be done in a systematic manner. The more specific the details included the better the possibility for data linkage and analyses. Systematic efforts such as a short follow-up survey sent at the completion of a Member request that is being implemented at the Lords Library provides a potentially useful source that can be linked to other data at the individual-level. However, it is worth noting that if the survey is only being asked to those making a request, it suggests they believe in the usefulness of Library services. Those never making a request by definition are never asked this survey, and so no insight can be made from this about why they do not use the Library. Further study comparing users and non-users to identify whether certain characteristics (e.g. length of membership, attendance) relate to usage or not would add to understanding. An alternative would be to interview all Members to identify their understanding of Library services and the useful of these, as well as reasons why they may not utilize these services. Regardless, there are myriad data sources which can be collected and used currently by the Library. However, to collect these data require some investment through person-hours. For collection of many of these sources, programs such as R can extract useful indicators. Documentation and message boards are extensive online, so it is largely a matter of human resource allocation.

\section{References}

Alemna, A.A. and Shouby, K.E. (2000), "An investigation into the information needs and information-seeking behaviour of members of Ghana's legislature", Library Management, Vol. 21, No. 5, pp. 235-240.

Appleton, L. (2017), Libraries and Key Performance Indicators: A Framework for Practitioners. Chandos Publishing: Kidlington, UK.

Brundin, M. (2005), "Democracy Building Activities in the Swedish Riksdag: the role of a parliamentary library" International Federation of Library Associations and Institutions Journal, Vol. 31, No. 1, pp. 19-27.

Comma Serema, B. (1999), "Matching MPs' information needs and information services in the House of Commons", Library Management, Vol. 20, No. 3, pp. 179-190. 
Chung, H-K. (2007), "Measuring the economic value of special libraries", The Bottom Line, Vol. 20, No. 1, pp. 30-44.

Gandomi, A. and Haider, M. (2015), "Beyond the hype: Big data concepts, methods, and analytics”, International Journal of Information Management, Vol. 35, No. 2, pp. 137144.

Greenhead, J. (2014), History of the House of Lords Library, Lords Library Note 2014/041, available at: http://researchbriefings.parliament.uk/ResearchBriefing/Summary/LLN2014-041 (accessed 27 July, 2018)

Johnston N (2017) The Parliamentary Constituencies (Amendment) Bill 2017-19. House of Commons Briefing Paper. Number CBP 08164, 1 December.

Kohl, E. (1991), "The Challenge of Change in Eastern Europe to the Parliamentary Libraries of the West" International Federation of Library Associations and Institutions Journal, Vol 17, No. 2, pp. 128-134.

LibLime Koha (2018) LibLime Koha ILS. Available at: www.koha.com (accessed 3 October 2018).

Manda, P.A. and Hilika, A.R. (2016), "Internet Access and Use in Political Discourse by the Members of Parliament in Tanzania" University of Dar es Salaam Library Journal, Vol. 11, No. 2, pp. 31-44.

Marcella, R., Carcary, I. and Baxter, G. (1999), “The information needs of United Kingdom Members of the European Parliament (MEPs)", Library Management, Vol. 20, No. 3, pp. 168-178.

Missingham R. (2005), "Libraries and economic value: a review of recent studies", Performance Measurement and Metrics, Vol. 6, No. 3, pp. 142-158.

Missingham, R. (2011), "Parliamentary library and research services in the 21st century: A Delphi study", International Federation of Library Associations and Institutions Journal, Vol. 35, No. 1, pp. 52-61.

Missingham, R. and Miskin, S. (2011), “An Informed Parliament: The Role of the Federal Parliamentary Library”, Australian Journal of Political Science, Vol. 46, No. 2, pp. 331339.

Mostert, J.B. (2005) "Parliamentary information sources, systems and services in South Africa" South African Journal of Libraries and Information Science, Vol. 71, No. 1, pp. 51-63.

Norton, P. (2003), "Cohesion without discipline: Party voting in the House of Lords", The Journal of Legislative Studies, Vol. 9, No. No. 4, pp. 57-72.

Orton, R., Marcella, R. and Baxter, G. (2000), “An observational study of the information seeking behaviour of members of Parliament in the United Kingdom", ASLIB proceedings, Vol. 52, No. 6, pp. 207-217.

Poll, R. and Payne, P. (2006), "Impact measures for libraries and information services", Library Hi Tech, Vol. 24, No. 4, pp. 547-562. 
Purvis, M. (2017), "Behind the scenes at the House of Lords Library" available at: https://parliamentsandlegislatures.wordpress.com/2017/03/22/house-of-lords-library (accessed 27 July, 2018)

R Core Team (2018), "R: A Language and Environment for Statistical Computing", available at: https://www.R-project.org (accessed 27 July, 2018)

Russell, M. and Sciara, M. (2007), "Why Does the Government get Defeated in the House of Lords?: The Lords, the Party System and British Politics", British Politics, Vol. 2, No. 3, pp. 299-322.

Russell, M. (2010), "A Stronger Second Chamber? Assessing the Impact of House of Lords Reform in 1999 and the Lessons for Bicameralism", Political Studies, Vol. 58, No. 5, pp. 866-885.

Ronai, I. and Bryant, M.N. (1992), "The Role of Hungary's Parliamentary Library in Fostering Democratic Decision Making”, Libri, Vol. 42, No. 2, pp. 136-143.

Shell D (2007) The House of Lords. Manchester: University of Manchester Press.

Silge, J. and Robinson, D. (2017), Text Mining with R: A Tidy Approach. O’Reilly Media, Inc: Sebastpol, California

SirsiDynix (2018) SirsiDynix Symphony. Available at: http://www.sirsidynix.com/products/sirsidynix-symphony (accessed 3 October 2018).

Showers, B. and Stone, G. (2014), "Safety in numbers: developing a shared analytics service for academic libraries", Performance Measurement and Metrics, Vol. 15, No. 1/2, pp. 13-22.

Watt, I. (2010), "Changing visions of parliamentary libraries: From the Enlightenment to Facebook" International Federation of Library Associations and Institutions Journal, Vol. 36, No. 1, pp. 47-60.

Zafar, M.S. (2009), "Information Seeking Behaviour of Member of Legislative Assembly of U.P. and Rajasthan: A Comparative Study", Unpublished Doctoral Thesis. Department of Library and Information Science, Aligarh Muslim University, Aligarh, India. 